\title{
Exercise Increases the Plasma Antioxidant Capacity of Adolescent Athletes
}

\author{
Anja Carlsohn ${ }^{\text {a, c }}$ Sascha Rohn ${ }^{d}$ Frank Bittmann $^{\mathrm{b}}$ Jens Raila ${ }^{\mathrm{a}}$ Frank Mayer $^{\mathrm{c}}$ \\ Florian J. Schweigert ${ }^{a}$ \\ a Department of Physiology and Pathophysiology, Institute of Nutritional Science, University of Potsdam, \\ Potsdam-Nuthetal, Departments of ${ }^{b}$ Regulative Physiology and Prevention, and ${ }^{\mathrm{C} S p o r t s}$ Medicine and \\ Orthopaedics, Institute of Sports Medicine and Prevention, University of Potsdam, Potsdam, and d Department of \\ Food Analysis, Institute of Food Technology and Food Chemistry, Technische Universität Berlin, Berlin, Germany
}

\section{Key Words}

Oxidative stress · Exercise-induced adaptations •

Competitive athletes $\cdot$ Antioxidants

\begin{abstract}
Background: The reactive oxygen species produced as a result of exercise might exceed an individual's antioxidant defence system. Various endogenous antioxidants are elevated in adult athletes, resulting in an improved antioxidant capacity. However, little is known about antioxidant defence in adolescents. The purpose of this study was to examine presumed adaptations of antioxidant capacity in exercising adolescents. Methods: Trolox-equivalent antioxidant capacity (TEAC), uric acid and nutritional antioxidants were measured in the plasma of 91 male and 98 female athletes (mean age $15.9 \pm 2.0$ years) and compared to those of 18 male and 22 female sedentary controls (mean age $16.3 \pm 2.1$ years). Antioxidant intake was calculated using 4-day dietary records. Results: Neither male nor female athletes showed differences in $\alpha$-tocopherol, $\beta$-carotene or ascorbate intake compared to controls. Plasma levels of $\alpha$-tocopherol and carotenoids in athletes and controls did not differ either. Nevertheless, athletes of both sexes had higher TEAC values than their respective controls (male athletes $1.48 \pm 0.22$
\end{abstract}

$\mathrm{mmol} / \mathrm{l}$ vs. male controls $1.23 \pm 0.19 \mathrm{mmol} / \mathrm{l}$, female athletes $1.47 \pm 0.20 \mathrm{mmol} / \mathrm{l}$ vs. female controls $1.15 \pm 0.04$ $\mathrm{mmol} / \mathrm{l}, \mathrm{p}<0.05)$. Conclusions: Regular exercise enhances antioxidant capacity in adolescent athletes, independently of their dietary antioxidant intake, which indicates activityrelated adaptations.

Copyright $\odot 2008$ S. Karger AG, Basel

\section{Introduction}

Reactive oxygen species (ROS) are produced within the body as a result of various physiological and pathological conditions. Because of their unpaired electrons, ROS are highly reactive and may destroy macromolecules, cells and tissues. Oxidative stress is known to be a risk factor for a variety of diseases, and an imbalance in redox state has been implicated in the development of muscle disturbances such as chronic fatigue syndrome or delayed onset of muscle soreness [1]. However, recent research suggests that ROS produced in contracting skeletal muscle play a pivotal role in adaptation to training, as they may activate redox-sensitive signalling pathways, which stimulate growth, differentiation, proliferation or apoptosis $[2,3]$. There is a rising body of evidence that the

\section{KARGER}

Fax +41613061234 E-Mail karger@karger.ch www.karger.com
(C) 2008 S. Karger AG, Basel

0250-6807/08/0532-0096\$24.50/0

Accessible online at:

www.karger.com/anm
Anja Carlsohn

Institute of Sports Medicine and Prevention

Department of Sports Medicine and Orthopaedics

Am Neuen Palais 10, DE-14469 Potsdam (Germany)

Tel. +49331977 1486, Fax +49 331977 1296, E-Mail carlsohn@uni-potsdam.de 
cellular redox state influences the contractile muscle function as redox-sensitive proteins are responsible for coupling the excitation and metabolic pathways $[4,5]$. A certain ROS concentration seems to be necessary to maintain normal muscle force and contractility $[4,6]$. However, the regulation of ROS concentration within narrow physiological limits might be an essential mechanism to assure cell function and prevent oxidative damage or muscular fatigue $[3,7]$.

Exercise has been associated with increased ROS formation as a result of elevated oxygen consumption $[8,9]$. During exhausting exercise, whole body oxygen consumption increases by 15 - to 20 -fold, while in the working muscles values of 100 - to 200 -fold above resting levels may be reached [10]. Exercise was subsequently believed to enhance ROS production because of activation of the mitochondrial respiratory chain [11]. However, there is a substantial body of evidence that sources other than mitochondrial leakage contribute considerably to exerciseinduced ROS generation [12]. During strenuous muscular work, the calcium-dependent xanthine oxidase pathway plays a pivotal role in superoxide formation [8]. Damaging exercise often entails an immune response [13] and contraction-induced myofibrillar disruptions result in the activation of various immune-responsive cells. Neutrophils migrating into the damaged muscle might further enhance ROS production as a result of their oxidative bursts [14]. Recent research indicates that ROS formation by membrane-bound oxidoreductases, such as $\mathrm{NAD}(\mathrm{P}) \mathrm{H}$ oxidase, is elevated the during contractile activity of skeletal muscle [15].

Although there is evidence that moderate physical activity might disrupt the redox balance [8], exercise-induced adaptations of antioxidant capacity in adults have been shown by numerous investigators. These adaptations include altered activities and gene expressions of antioxidant enzymes such as superoxide dismutase, catalase or glutathione peroxidase $[16,17]$. An insufficient antioxidant defence system may allow the development of oxidative stress, which is associated with metabolic alterations that lead to poorer physical performance in athletes [18]. Athletes are at particular risk of exceeding their antioxidant capacity when they train too intensely or perform exercises to which they are not accustomed. This is accompanied by increased lipid peroxidation and muscle damage $[19,20]$. However, there are conflicting results concerning the effects of nutritional antioxidants or supplements on the prevention of post-exercise oxidative stress [21, 22]. Moreover, antioxidant supplementation might impair ROS formation as the underlying mecha- nism for training adaptation and elevated expression of antioxidant enzymes $[2,5]$.

There is little information available regarding exercise-induced adaptations of the ROS defence system in adolescent and child athletes. Precise knowledge about the assumed training-induced up-regulation of endogenous antioxidants in exercising children could be helpful in preventing overtraining, fatigue and muscular damage in teenage athletes. The main objective of this study was to determine whether exercise-dependent alterations within the antioxidant defence capacity are observed in children and adolescents exercising regularly. Furthermore, we addressed the question whether the type of exercise, age, gender or the number of weekly training sessions influence the antioxidant capacity of teenage athletes.

\section{Subjects and Methods}

Subjects, Physical Activity and Dietary Intake

The study was approved by the Ethics Committee of the University of Potsdam and the Brandenburg Ministry of Education, Youth and Sports. Written informed consent was given by all subjects, and their parents in cases where participants were underaged. Volunteers were recruited either from students at a school for elite sports (athletes, $\mathrm{n}=189$ ) or from a school with no emphasis on physical activity (sedentary controls, $\mathrm{n}=40$ ). The mean age of participants was $15.9 \pm 2.0$ years for athletes and $16.3 \pm 2.1$ years for controls. Athletes represented 14 different disciplines, and were placed into the following groups according to their main exercise emphasis: (1) endurance athletes $(n=84)$, (2) quickstrength athletes $(\mathrm{n}=48),(3)$ athletes involved in ballgames $(\mathrm{n}=$ $41)$, and (4) alumni athletes $(n=16)$ having retired from a competitive career but still engaging in moderate physical activity. Physical activity was evaluated on the basis of self-report of the number of training sessions per week. Volunteers were divided into the following 4 activity levels: (1) non-active ( $0-2 \mathrm{~h}$ of sports/ week), (2) moderately active (2-6 h of sports/week), (3) midrange-performance athletes (7-12 training sessions/week) and (4) high-performance athletes ( $>12$ training sessions/week).

Individual supply of energy, macro- and micronutrients was assessed using a 4-day dietary protocol, which discriminated between cooked and uncooked fruits and vegetables [23]. Nutritional antioxidant intake by habitual diet was calculated based on the German Food Code and Nutrition Database BLS II.3, additional supply was quantified by a supplement questionnaire.

Blood Sample Collection and Anthropometric Measurements

Blood sample collection was performed after overnight fasting and before the first training session of the day. Blood was drawn from an antecubital vein into pre-chilled test tubes with EDTA as anticoagulant (Kabevette E301, Kabe, Nümbrecht-Elsenroth, Germany). Plasma was obtained by centrifugation for $15 \mathrm{~min}$ at $2,500 \mathrm{~g}$, and analysis aliquots were stored at $-80^{\circ} \mathrm{C}$. Height, weight and body composition were measured in the morning as fasting 
values. Percentage body fat was determined using the BIA 2000 M multi-frequency body-composition analyzer (Data Input, Frankfurt-Main, Germany).

Analysis of $\alpha$-Tocopherol, Carotenoids, Uric Acid and Total Antioxidant Capacity

Plasma levels of carotenoids and $\alpha$-tocopherol were analyzed within a month after blood sample collection. For separation and quantification of $\alpha$-tocopherol and carotenoids (lutein, zeaxanthin, $\alpha$-and $\beta$-carotene, $\beta$-cryptoxanthin and lycopene) a modified reverse-phased HPLC system was used, as previously described [24]. Uric acid quantification was carried out on Olympus AU 600 using the Uricase-PAP test (Olympus Europe GmbH, Hamburg, Germany). Plasma antioxidant capacity was determined by a modified Trolox-equivalent antioxidant capacity assay and expressed as Trolox equivalents (TE) as described elsewhere [25].

\section{Statistical Analysis}

The results are expressed as means \pm standard deviations. All statistical calculations were carried out on SPSS 14.0 for Windows. The unpaired Student t test (athletes vs. controls) at 95\% confidence interval and Kruskall-Wallis test were used to assess differences between the groups. Correlations were analysed using Pearson's correlation coefficient.

\section{Results}

\section{Subject Characteristics, Physical Activity and}

\section{Macronutrient Intake}

There were no significant differences in age, BMI or percentage body fat between athletes and sedentary controls. Detailed characteristics are listed in table 1. As expected, most of the athletes fell into 'mid-range performance' or 'high performance' categories (fig. 1). For males, energy and macronutrient intake was comparable between the different discipline groups, alumni athletes and sedentary controls. Among the athletes, some discipline-specific variations in energy intake and proportion of macronutrients were found. Except for alumni athletes, females had similar energy and macronutrient supply in their diets. Alumni female athletes consumed significantly less carbohydrate, protein and fat (all p < 0.05), resulting in a lower total energy intake (table 2).

\section{Dietary Antioxidant Intake}

The habitual diets of the males involved in various sports did not differ in their nutritional antioxidant content (table 2). The low intake of foods rich in energy and fat by female alumni athletes was associated with a decreased consumption of dietary antioxidants (table 2). Increase in total energy intake was accompanied by improved supply of $\beta$-carotene and vitamins $\mathrm{C}$ and $\mathrm{E}$ (ta-

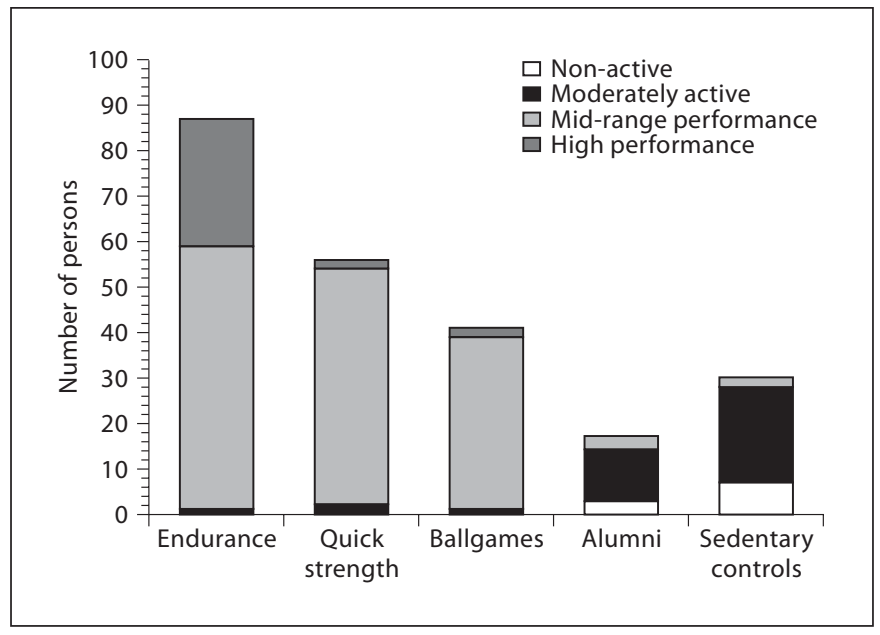

Fig. 1. Physical activity within the discipline groups and sedentary controls.

Table 1. Characteristics of subjects within the different discipline groups

\begin{tabular}{llll}
\hline Sports type & $\begin{array}{l}\text { Age } \\
\text { years }\end{array}$ & BMI & $\begin{array}{l}\text { Body fat } \\
\%\end{array}$ \\
\hline Males & & & \\
$\quad$ Endurance & $15.5 \pm 2.0$ & $21.3 \pm 2.8$ & $12.3 \pm 6.0$ \\
$\quad$ Quick strength & $15.4 \pm 1.6$ & $21.5 \pm 2.7$ & $11.7 \pm 6.5$ \\
$\quad$ Ballgames & $15.6 \pm 1.8$ & $20.9 \pm 2.8$ & $10.3 \pm 6.0$ \\
$\quad$ Alumni & $18.8 \pm 1.2^{*}$ & $22.3 \pm 2.7$ & $14.2 \pm 5.1$ \\
$\quad$ Controls & $16.2 \pm 2.3$ & $22.0 \pm 5.0$ & $14.5 \pm 8.4$ \\
Females & & & \\
$\quad$ Endurance & $15.6 \pm 2.0^{\mathrm{a}}$ & $20.5 \pm 2.2$ & $20.8 \pm 6.3$ \\
$\quad$ Quick strength & $16.5 \pm 1.8$ & $21.1 \pm 2.0$ & $22.5 \pm 3.8$ \\
$\quad$ Ballgames & $16.1 \pm 1.8^{\mathrm{b}}$ & $21.2 \pm 2.0$ & $23.2 \pm 4.4$ \\
$\quad$ Alumni & $17.7 \pm 1.4^{\mathrm{a}, \mathrm{b}}$ & $20.4 \pm 1.3$ & $22.3 \pm 4.0$ \\
Controls & $16.3 \pm 1.9$ & $20.9 \pm 2.2$ & $23.3 \pm 5.5$ \\
\hline
\end{tabular}

Data are means \pm SD. The same superscript letters indicate significant differences at the level $\mathrm{p}<0.05$. ${ }^{*}$ Male alumni athletes were significantly older than other male groups.

ble 3). Non-dietary antioxidant intake by supplements was negligible in both athletes and controls.

\section{Plasma Content of Nutritional Antioxidants}

There were no differences in plasma carotenoid and $\alpha$-tocopherol levels in athletes versus sedentary controls. Among the athletes, male high-perfomance athletes had higher $\beta$-carotene, total lycopene and total carotenoid levels compared to moderately active students $(\mathrm{p}<0.05)$. 
Table 2. Macronutrient intake and supply with nutritional antioxidants within the various discipline groups

\begin{tabular}{|c|c|c|c|c|c|c|c|}
\hline Sports type & $\begin{array}{l}\text { Energy } \\
\text { MJ/day }\end{array}$ & $\begin{array}{l}\text { Carbohydrate } \\
\text { g/day }\end{array}$ & $\begin{array}{l}\text { Protein } \\
\text { g/day }\end{array}$ & $\begin{array}{l}\text { Fat } \\
\text { g/day }\end{array}$ & $\begin{array}{l}\beta \text {-Carotene } \\
\mathrm{mg} / \text { day }\end{array}$ & $\begin{array}{l}\text { Vitamin E } \\
\text { mg/day }\end{array}$ & $\begin{array}{l}\text { Vitamin C } \\
\text { mg/day }\end{array}$ \\
\hline \multicolumn{8}{|l|}{ Male } \\
\hline Endurance & $12.9 \pm 4.8^{\mathrm{a}}$ & $397 \pm 146$ & $125 \pm 55^{\mathrm{a}}$ & $105 \pm 45^{\mathrm{a}, \mathrm{b}}$ & $5.5 \pm 3.9$ & $21.1 \pm 10.7$ & $251 \pm 180$ \\
\hline Quick strength & $10.4 \pm 1.7^{\mathrm{a}}$ & $353 \pm 58$ & $98 \pm 20$ & $71 \pm 20^{\mathrm{a}}$ & $4.4 \pm 2.0$ & $21.3 \pm 10.2$ & $228 \pm 79$ \\
\hline Ballgames & $13.4 \pm 5.7$ & $424 \pm 165$ & $120 \pm 58$ & $108 \pm 54$ & $3.0 \pm 2.4$ & $33.3 \pm 21.2$ & $238 \pm 143$ \\
\hline Alumni & $11.4 \pm 1.9$ & $390 \pm 95$ & $101 \pm 17$ & $75 \pm 11^{b}$ & $3.4 \pm 2.2$ & $15.7 \pm 6.1$ & $159 \pm 82$ \\
\hline Controls & $10.7 \pm 3.9$ & $335 \pm 120$ & $91 \pm 32^{\mathrm{a}}$ & $90 \pm 38$ & $4.8 \pm 2.6$ & $15.7 \pm 7.1$ & $185 \pm 115$ \\
\hline \multicolumn{8}{|l|}{ Female } \\
\hline Endurance & $9.0 \pm 2.1$ & $283 \pm 76$ & $86 \pm 21$ & $70 \pm 24$ & $4.9 \pm 3.1$ & $18.8 \pm 12.3$ & $197 \pm 124$ \\
\hline Quick strength & $9.4 \pm 2.9$ & $306 \pm 95$ & $82 \pm 27$ & $72 \pm 26$ & $3.9 \pm 3.1$ & $16.9 \pm 9.3$ & $186 \pm 108$ \\
\hline Ballgames & $9.7 \pm 2.7$ & $310 \pm 101$ & $93 \pm 27$ & $73 \pm 24$ & $4.3 \pm 3.4$ & $17.2 \pm 7.2$ & $172 \pm 106$ \\
\hline Alumni & $6.5 \pm 1.5^{*}$ & $217 \pm 72^{*}$ & $60 \pm 15^{*}$ & $46 \pm 8^{*}$ & $2.8 \pm 1.5$ & $8.9 \pm 2.9^{*}$ & $102 \pm 60$ \\
\hline Controls & $8.9 \pm 2.5$ & $281 \pm 75$ & $78 \pm 28$ & $73 \pm 24$ & $4.9 \pm 3.8$ & $15.2 \pm 5.7$ & $164 \pm 89$ \\
\hline
\end{tabular}

Data are means $\pm \mathrm{SD}$. The same superscript letters in one column indicate significant intra-gender differences $(\mathrm{p}<0.05)$.

* Female alumni athletes showed significant lower intake of energy, carbohydrates, protein, fat and vitamin E compared to all other groups, except for carbohydrates and protein compared to sedentary controls.

Table 3. Intake and plasma levels of dietary antioxidants and plasma antioxidant capacity (TEAC) depending on physical activity

\begin{tabular}{|c|c|c|c|c|c|c|c|c|c|c|}
\hline \multirow[t]{2}{*}{ Activity level } & \multicolumn{4}{|c|}{ Dietary intake } & \multicolumn{6}{|c|}{ Plasma levels } \\
\hline & $\begin{array}{l}\text { energy } \\
\text { MJ/day }\end{array}$ & $\begin{array}{l}\beta \text {-carotene } \\
\mathrm{mg} / \text { day }\end{array}$ & $\begin{array}{l}\text { vitamin } \mathrm{E} \\
\mathrm{mg} / \mathrm{day}\end{array}$ & $\begin{array}{l}\text { vitamin } \mathrm{C} \\
\mathrm{mg} / \text { day }\end{array}$ & $\begin{array}{l}\alpha \text {-carotene } \\
\mu \mathrm{mol} / \mathrm{l}\end{array}$ & $\begin{array}{l}\beta \text {-carotene } \\
\mu \mathrm{mol} / \mathrm{l}\end{array}$ & $\begin{array}{l}\text { total } \\
\text { lycopene }^{1} \\
\mu \mathrm{mol} / 1\end{array}$ & $\begin{array}{l}\text { total } \\
\text { carotenoids }{ }^{2} \\
\mu \mathrm{mol} / 1\end{array}$ & $\begin{array}{l}\alpha \text {-tocopherol } \\
\mu \mathrm{mol} / \mathrm{l}\end{array}$ & $\begin{array}{l}\text { Trolox- } \\
\text { equivalents } \\
\text { mmol/l }\end{array}$ \\
\hline \multicolumn{11}{|l|}{ Males $^{3}$} \\
\hline Moderately active & $10.6 \pm 2.7^{\mathrm{a}}$ & $3.8 \pm 2.3$ & $17.5 \pm 7.8^{\mathrm{a}}$ & $158 \pm 83^{\mathrm{a}}$ & $0.10 \pm 0.07$ & $0.55 \pm 0.27^{\mathrm{a}}$ & $0.19 \pm 0.07^{\mathrm{b}}$ & $1.17 \pm 0.49^{c}$ & $18.05 \pm 3.23$ & $1.28 \pm 0.23^{\mathrm{a}, \mathrm{b}}$ \\
\hline $\begin{array}{l}\text { Mid-range } \\
\text { performance }\end{array}$ & $11.9 \pm 4.7^{\mathrm{b}}$ & $5.0 \pm 3.8$ & $21.1 \pm 13.9$ & $234 \pm 173$ & $0.10 \pm 0.07$ & $0.67 \pm 0.39$ & $0.22 \pm 0.08$ & $1.36 \pm 0.56$ & $18.83 \pm 5.08$ & $1.45 \pm 0.20^{\mathrm{a}}$ \\
\hline High performance & $15.1 \pm 3.9^{\mathrm{a}, \mathrm{b}}$ & $4.9 \pm 3.1$ & $26.8 \pm 9.3^{\mathrm{a}}$ & $288 \pm 137^{\mathrm{a}}$ & $0.11 \pm 0.05$ & $0.88 \pm 0.57^{\mathrm{a}}$ & $0.25 \pm 0.09^{b}$ & $1.65 \pm 0.74^{c}$ & $20.38 \pm 4.66$ & $1.50 \pm 0.22^{\mathrm{b}}$ \\
\hline \multicolumn{11}{|l|}{ Females } \\
\hline Non-active & $8.8 \pm 2.6$ & $4.1 \pm 2.2$ & $16.3 \pm 6.6$ & $176 \pm 73$ & $0.16 \pm 0.09$ & $0.67 \pm 0.30$ & $0.37 \pm 0.40$ & $1.74 \pm 0.76$ & $20.29 \pm 2.33$ & $1.13 \pm 0.03^{c, d}$ \\
\hline Moderately active & $7.6 \pm 2.5^{c, d}$ & $4.0 \pm 4.0$ & $11.5 \pm 4.9^{c, d}$ & $123 \pm 89$ & $0.14 \pm 0.08$ & $0.69 \pm 0.37$ & $0.22 \pm 0.07$ & $1.57 \pm 0.58$ & $18.38 \pm 3.41^{\mathrm{d}}$ & $1.17 \pm 0.04^{\mathrm{a}, \mathrm{b}}$ \\
\hline $\begin{array}{l}\text { Mid-range } \\
\text { performance }\end{array}$ & $9.3 \pm 2.6^{c}$ & $4.3 \pm 3.1$ & $17.1 \pm 9.0^{c}$ & $185 \pm 110$ & $0.12 \pm 0.07$ & $0.87 \pm 0.83$ & $0.22 \pm 0.08$ & $1.72 \pm 1.00$ & $20.27 \pm 4.89$ & $1.46 \pm 0.18^{\mathrm{a}, \mathrm{c}}$ \\
\hline High performance & $10.4 \pm 1.6^{\mathrm{d}}$ & $5.6 \pm 3.6$ & $24.4 \pm 19.2^{\mathrm{d}}$ & $200 \pm 133$ & $0.17 \pm 0.12$ & $1.11 \pm 0.86$ & $0.25 \pm 0.13$ & $1.97 \pm 1.03$ & $23.06 \pm 5.66^{\mathrm{d}}$ & $1.52 \pm 0.27^{\mathrm{b}, \mathrm{d}}$ \\
\hline $\begin{array}{l}\text { Data are means } \pm \\
{ }^{1} \text { Total lycopene is } \\
{ }^{2} \text { Total carotenoids } \\
{ }^{3} \text { Only one male no }\end{array}$ & $\begin{array}{l}\text { SD. The sa } \\
\text { the sum of } \\
\text { s are the su } \\
\text { on-active } v\end{array}$ & $\begin{array}{l}\text { is-and tro } \\
\text { of lutein, }\end{array}$ & eaxanthin & and $\beta-$ & ee, $\beta-\mathrm{cl}$ & $\begin{array}{r}\text { cant dif } \\
\text { xanthir }\end{array}$ & aces ( $\mathrm{p}<$ & & & \\
\hline
\end{tabular}

This was not observed in females, except for the higher $\alpha$-tocopherol levels in the high-performance athletes compared to moderately active females $(\mathrm{p}<0.05$, table 3$)$. We observed no correlation between TEAC values and elevated plasma levels of $\alpha$-tocopherol or carotenoids.

\section{Plasma Antioxidant Capacity (TEAC)}

Athletes and those having abandoned their competitive career (alumni) showed significantly $(\mathrm{p}<0.05)$ ele- vated plasma antioxidant capacity in both males (1.48 \pm $0.22 \mathrm{mmol} \mathrm{TE} / \mathrm{l})$ and females $(1.47 \pm 0.20 \mathrm{mmol} \mathrm{TE} / \mathrm{l})$ compared to sedentary controls $(1.23 \pm 0.19 \mathrm{mmol} \mathrm{TE} / \mathrm{l}$ for males and $1.15 \pm 0.04 \mathrm{mmol} \mathrm{TE} / \mathrm{l}$ for females; fig. 2). No differences in TEAC values were observed between endurance athletes, quick-strength athletes and ballgame players (fig. 3). There was no evidence for gender-dependent variations in antioxidant capacity (table 3). In both male (Pearson's correlation $\mathrm{r}=0.47, \mathrm{p}<0.05$ ) and female 


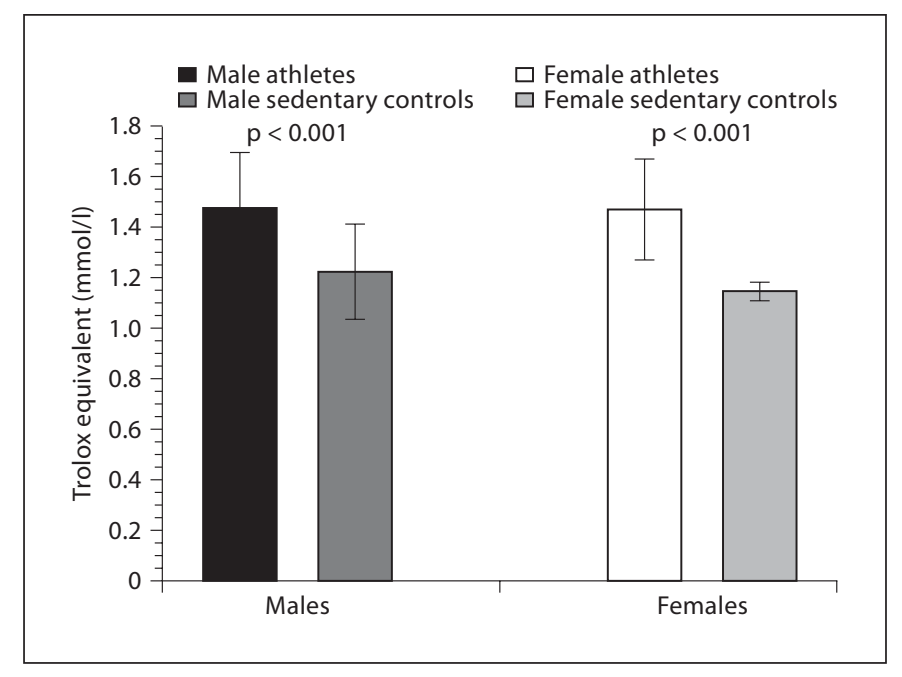

Fig. 2. Significantly elevated plasma TEAC was found in athletes compared to controls.

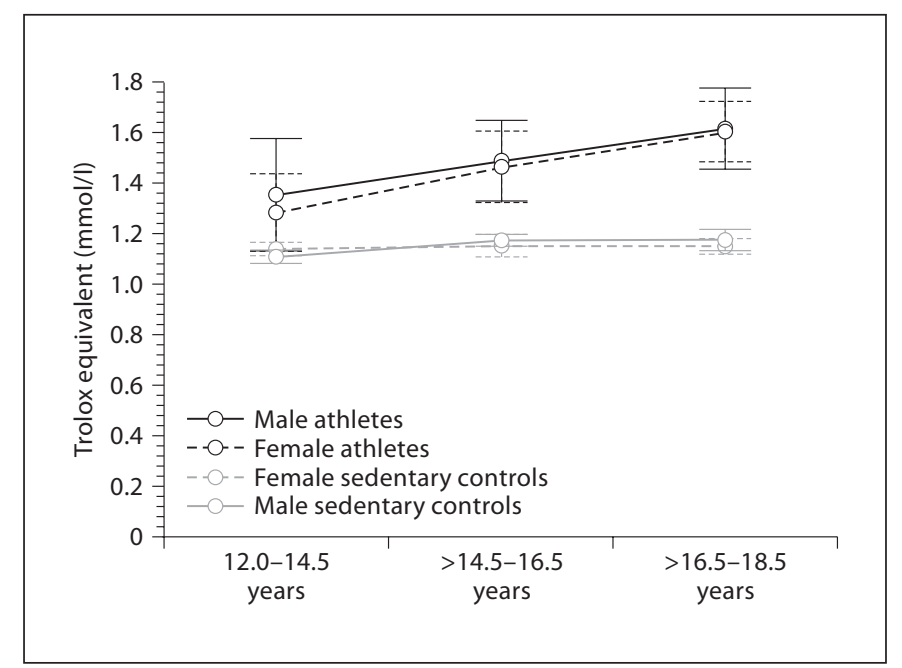

Fig. 4. TEAC values behave differently in athletes and non-athletes with rising age.

athletes $(r=0.63, p<0.05)$ the antioxidant capacity increased with rising age. However, this apparently age-dependent elevation of plasma antioxidant capacity was not seen in non-athletes (fig. 4). There were no differences observed for uric acid between athletes and controls (male athletes $333 \pm 125 \mu \mathrm{mol} / \mathrm{l}$ vs. male controls $315 \pm$ $65 \mu \mathrm{mol} / \mathrm{l}$, female athletes $232 \pm 42 \mu \mathrm{mol} / \mathrm{l}$ vs. female controls $243 \pm 42 \mu \mathrm{mol} / \mathrm{l})$.

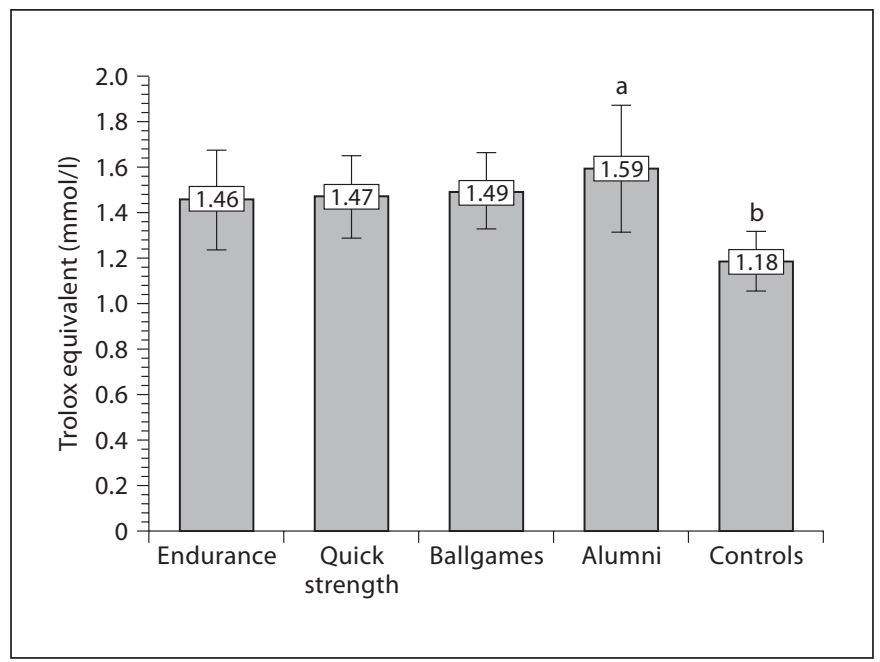

Fig. 3. TEAC with regard to different sports. ${ }^{\text {a }}$ Significant elevation compared to the other groups; ${ }^{\mathrm{b}}$ significant decline compared to the other groups.

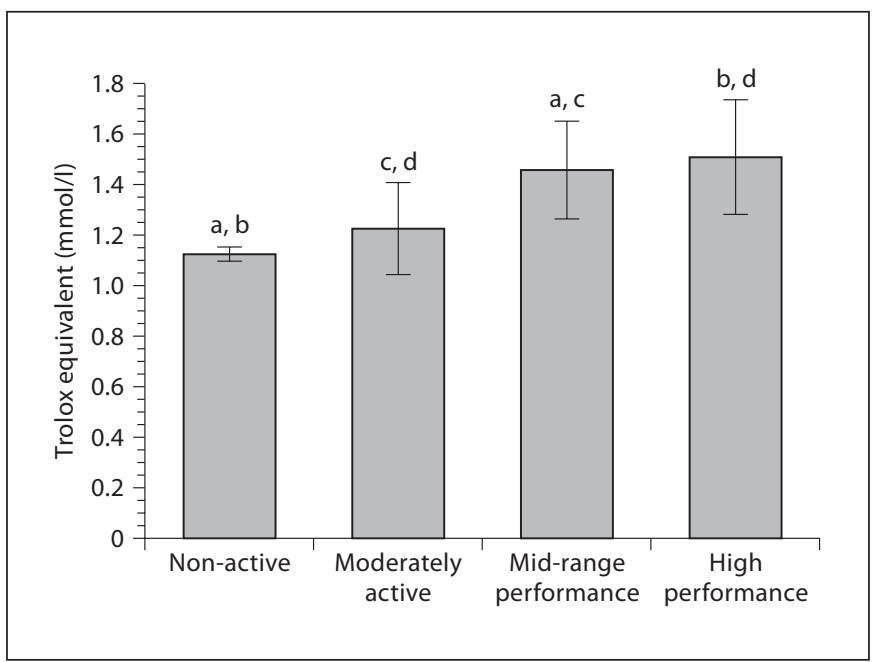

Fig. 5. TEAC correlates with level of training. The same letters illustrate significant differences $(\mathrm{p}<0.05)$.

Finally, a significant correlation between the number of training sessions per week and antioxidant capacity was obvious $(\mathrm{r}=0.41, \mathrm{p}<0.05)$. The scale of antioxidant plasma capacity ranged from $1.13 \pm 0.03 \mathrm{mmol} \mathrm{TE} / \mathrm{l}$ in the non-active to $1.51 \pm 0.23 \mathrm{mmol} \mathrm{TE} / \mathrm{l}$ in the high-performance athletes (fig. 5). This finding turned out to be significant for both the sexes as well as for athletes and non-athletes alike (table 3). 


\section{Discussion}

It is generally accepted that plasma antioxidant capacity does not reflect the cellular redox state. However, with the limitations of measuring total plasma antioxidant capacity in mind, we applied the TEAC assay to examine whether and to what extend the antioxidant capacity of children and adolescents is adapted to their ambitious training regime [26]. The TEAC assay has been shown to give reliable data for assessing antioxidant response to exercise [27], disease [28] or dietary intervention [29] in different human body fluids. Athletes and non-athletes showed similar characteristics according to age, anthropometric data, energy and macronutrient intake, which indicates TEAC modulations independent of diet. In athletes, but not in sedentary controls, antioxidant capacity increased remarkably with rising age. Thus, we suppose the putative age dependency of antioxidant capacity was not only due to maturation, but rather was a result of an age-associated component. The training regime might be such an age-associated factor that can influence the antioxidant defence system. In this respect, the duration, intensity and number of anaerobic-lactacid training sessions per week is assumed to increase with rising age in young athletes. The hypothesis of an age-independent rise in plasma TEAC is supported by our finding that these values increase continuously in athletes with the number of weekly exercises. High-performance and midrange-performance athletes have significantly elevated antioxidant capacities compared with non-active and moderately active students. The raise in antioxidant capacity with increasing training effort suggests a dose-dependent mechanism of adaptations to exercise-induced increase in ROS formation.

Plasma carotenoids were similar to other study cohorts of comparable age and reflect a sufficient intake of fruits and vegetables [30]. Although TEAC values are primarily influenced by diverse water-soluble substances, we measured fat-soluble plasma antioxidants such as carotenoids and tocopherols. A lack of difference in plasma carotenoid content reflects a similar intake of plant foods and plant-derived antioxidants in athletes and controls, as it is well documented that plasma carotenoids serve as biomarkers for the habitual consumption of fruits and vegetables [31]. All groups met the daily recommendations for the intake of vitamins $\mathrm{C}$ and $\mathrm{E}$. Among our wellnourished study population that was homogenous according to nutritional antioxidant intake, we could not find any correlation between TEAC and $\alpha$-tocopherol, ascorbic acid and $\beta$-carotene consumption, or with plas- ma levels of $\alpha$-tocopherol and carotenoids. The absence of differences in the dietary antioxidant intake between athletes and controls suggests a nutrition-independent, exercise-associated TEAC elevation. In conclusion, we propose that exercising itself might influence TEAC values in the plasma of adolescent athletes, as has been shown in adults [32, 33]. However, assumed adaptations need to be studied in untrained adolescents using training schedules to evaluate response to standardized exercises.

The data presented here do not support the idea of gender differences in the antioxidant defence systems in athletes, which is in agreement with a recently published report [34]. Although both sedentary and exercising females have lower plasma TEAC levels, this finding did not reach statistical significance, and in a detailed analysis conflicting results within the different discipline groups were observed. This outcome is in contrast to the thesis that females might have a higher antioxidant potential due to the antioxidant effect of sex hormones such as $17 \beta$-estradiol [35]. Katalinic et al. [36] observed a higher antioxidant tissue capacity and lower susceptibility to oxidative modulations in female rats. In humans, postmenopausal women seem to be more susceptible to oxidative stress than premenopausal women, indicating a relationship between oestrogens and antioxidant capacity [37]. Conflicting statements concerning the influence of sex hormones on the female redox balance might be due to the potential of oestrogens to act both as antioxidants and pro-oxidants [38]. Moreover, the possibility of a decreased oestrogen blood concentration in female athletes due to exercise-induced hormonal misbalances must be taken into consideration [39].

When comparing antioxidant capacity of athletes in different sports, no difference could be revealed. Although different sports are known to affect ROS formation unequally, athletes had almost identical mean TEAC values, independently of the chosen discipline. This finding might be due to the fact that young athletes in all sports complete a high proportion of non-specific fundamental training that includes similar elements. Almost all the above-mentioned disciplines require components of both aerobic and anaerobic endurance, speed, quick strength, strength endurance and strength in general. Thus, having studied the athletes during a semi-specific period of training accentuation in their yearly cycle, no discipline-specific variances could be anticipated. In addition, we cannot provide any evidence-based explanation for the significant TEAC elevation in alumni athletes compared to active athletes and controls. However, as 
those athletes have been retiring from competitive career no longer than 1 year prior to blood sample collection, a lag phase before reversal of adaptation can be anticipated. No data are available about existence and duration of this assumed lag phase. Moreover, alumni athletes involved in the study still showed above-average physical activity, which might have been sufficient to inhibit reversal of adaptation, keeping antioxidant capacity at a high level. Yet already one single intensive exercise programme is known to reduced GSH levels or decrease the GSH-toGSSG ratio [40]. An increased enzymatic antioxidant defence concomitant with a lower reduction of GSH-toGSSG ratio resulting from lower exercise intensity and frequency might result in the higher overall antioxidant capacity of alumni athletes compared to active competitors.

It is not possible to say with certainty which endogenous antioxidant modifications are responsible for the raise in TEAC values in our subjects. Calculating the mean serum concentrations and measuring the antioxidant capacity of the following substances, Miller et al. [41] suggested that albumin (43\%), uric acid (33\%) and vitamin $\mathrm{E}(3 \%)$ might be the most relevant antioxidants to influence serum TEAC values. However, in another study their contribution was estimated to be lower, at $28 \%$ for albumin, $19 \%$ for uric acid and $2 \%$ for $\alpha$-tocopherol [42]. As production of uric acid is increased during exercise due to increased AMP breakdown, it could be assumed that the observed modulation of plasma antioxidant capacity is primarily based on increased uric acid levels. However, significant differences in plasma uric acid content between athletes and controls are lacking. Thus, we suggest that antioxidants other than uric acid might be modified. There is evidence that exercise-induced TEAC elevation might be caused by induction of plasmatic enzymes, as has been shown for superoxide dismutase [32, 43, 44], glutathione reductase [45] and low molecular weight compounds such as plasma thiols [46].

\section{Conclusion}

Our results indicate that regular physical activity evokes adaptations in the antioxidant defence system that appear to be independent of diet and age. Further research is required, including investigations into enzyme activities, glutathione content and the behaviour of other endogenous antioxidants to analyse the mechanisms involved in the plasma antioxidant defence system. The evaluation of oxidative modulations is necessary to answer the question whether the above-demonstrated adaptations of the antioxidant defence system are sufficient to protect adolescent athletes who are highly exposed to ROS from subsequent oxidative damage.

\section{Acknowledgements}

The authors are grateful to the participants and the Olympic Support Centre Potsdam for their cooperation. We thank Dr. Martin Kern from the Medical Laboratory Potsdam for the medical support during blood sample collection, and Andrea Hurtienne and Mark Meltendorf for their technical assistance. This study was supported by research grants from the German Institute of Sport Science (BISp) and the Brandenburg Ministry of Education, Youth and Sports.

\section{References}

1 Jammes Y, Steinberg JG, Mambrini O, et al: Chronic fatigue syndrome: assessment of increased oxidative stress and altered muscle excitability in response to incremental exercise. J Intern Med 2005;257:299-310.

-2 Ji LL, Gomez-Cabrera MC, Steinhafel N, Vina J: Acute exercise activates nuclear factor (NF)-kappaB signaling pathway in rat skeletal muscle. FASEB J 2004;18:14991506.

- 3 Andrade FH, Reid MB, Westerblad H: Contractile response of skeletal muscle to low peroxide concentrations: myofibrillar calcium sensitivity as a likely target for redoxmodulation. FASEB J 2001;15:309-311.

\footnotetext{
-4 Clanton TL, Zuo L, Klawitter P: Oxidants and skeletal muscle function: physiologic and pathophysiologic implications. Proc Soc Exp Biol Med 1999;222:253-262.

$\checkmark 5$ Niess AM, Simon P: Response and adaptation of skeletal muscle to exercise: the role of reactive oxygen species. Front Biosci 2007; 12:4826-4838.

6 Reid MB: Invited review: redox modulation of skeletal muscle contraction: what we know and what we don't. J Appl Physiol 2001;90: 724-731.

7 Jackson MJ: Reactive oxygen species and redox regulation of skeletal muscle adaptations to exercise. Philos Trans R Soc Lond B Biol Sci 2005;360:2285-2291.
}

8 Aguilo A, Tauler P, Fuentespina E, Tur JA, Cordova A, Pons A: Antioxidant response to oxidative stress induced by exhaustive exercise. Physiol Behav 2005;84:1-7.

-9 Clarkson PM, Thompson HS: Antioxidants: what role do they play in physical activity and health? Am J Clin Nutr 2000;72:637S646S.

10 Sen CK: Oxidants and antioxidants in exercise. J Appl Physiol 1995;79:675-686.

-11 Tonkonogi M, Walsh B, Svensson M, Sahlin $\mathrm{K}$ : Mitochondrial function and antioxidative defence in human muscle: effects of endurance training and oxidative stress. J Physiol 2000;528:379-388. 
12 Bailey DM, Young IS, McEneny J, et al: Regulation of free radical outflow from an isolated muscle bed in exercising humans. Am J Physiol Heart Circ Physiol 2004;287: H1689-H1699.

-13 Tauler P, Aguilo A, Cases N, Sureda A, Gimenez F, Villa G, Cordova A, Biescas AP: Acute phase immune response to exercise coexists with decreased neutrophil antioxidant enzyme defences. Free Radic Res 2002; 36:1101-1107.

-14 Korhonen PA, Lilius EM, Hyyppä S, Räsänen LA, Pösö AR: Production of reactive oxygen species in neutrophils after repeated bouts of exercise in standardbred trotters. J Vet Med A Physiol Pathol Clin Med 2000;47:565573.

15 Kerkweg U, Petrat F, Korth HG, de Groot H: Disruption of skeletal myocytes initiates superoxide release: contribution of NADPH oxidase. Shock 2007;27:552-558

-16 Leeuwenburgh C, Hollander J, Leichtweis S, et al: Adaptations of glutathione antioxidant system to endurance training are tissue and muscle fiber specific. Am J Physiol 1997;272: R363-R369.

17 Miyazaki H, Oh-ishi S, Ookawara T, et al: Strenuous endurance training in humans reduces oxidative stress following exhausting exercise. Eur J Appl Physiol 2001;84:1-6.

$\checkmark 18$ Chevion S, Moran DS, Heled Y, et al: Plasma antioxidant status and cell injury after severe physical exercise. Proc Natl Acad Sci USA 2003;100:5119-5123.

19 Palazzetti S, Richard MJ, Favier A, Margaritis I: Overloaded training increases exerciseinduced oxidative stress and damage. Can J Appl Physiol 2003;28:588-604.

-20 Close GL, Ashton T, Cable T, et al: Effects of dietary carbohydrate on delayed onset muscle soreness and reactive oxygen species after contraction induced muscle damage. $\mathrm{Br} J$ Sports Med 2005;39:948-953.

-21 Watson TA, Callister R, Taylor RD, et al: Antioxidant restriction and oxidative stress in short-duration exhaustive exercise. Med Sci Sports Exerc 2005;37:63-71.

-22 Atalay M, Lappalainen J, Sen CK: Dietary antioxidants for the athlete. Curr Sports Med Rep 2006;5:182-186.

-23 Koebnick C, Wagner K, Thielecke F, et al: An easy-to-use semiquantitative food record validated for energy intake by using doubly labelled water technique. Eur J Clin Nutr 2005;59:989-995.
24 Schweigert FJ, Steinhagen B, Raila J, et al: Concentrations of carotenoids, retinol and alpha-tocopherol in plasma and follicular fluid of women undergoing IVF. Hum Reprod 2003;18:1259-1264.

25 Rohn S, Rawel HM, Kroll J: Antioxidant activity of protein-bound quercetin. J Agric Food Chem 2004;52:4725-4729.

26 Halliwell B, Whiteman M: Measuring reactive species and oxidative damage in vivo and in cell culture: how should you do it and what do the results mean? Br J Pharmacol 2004; 142:231-255

27 Simpson RJ, Wilson MR, Black JR, et al: Immune alterations, lipid peroxidation, and muscle damage following a hill race. Can Appl Physiol 2005;30:196-211.

28 Lands LC, Grey VL, Grenier C: Total plasma antioxidant capacity in cystic fibrosis. Pediatr Pulmonol 2000;29:81-87.

29 Arendt BM, Ellinger S, Kekic K, et al: Single and repeated moderate consumption of native or dealcoholized red wine show different effects on antioxidant parameters in blood and DNA strand breaks in peripheral leukocytes in healthy volunteers: a randomized controlled trial. Nutr J 2005;4:33.

30 Ford ES, Gillespie C, Ballew C, et al: Serum carotenoid concentrations in US children and adolescents. Am J Clin Nutr 2002;76: 818-827.

31 Al-Delaimy WK, Ferrari P, Slimani N, et al: Plasma carotenoids as biomarkers of intake of fruits and vegetables: individual-level correlations in the European Prospective Investigation into Cancer and Nutrition (EPIC). Eur J Clin Nutr 2005;59:1387-1396.

32 Brites FD, Evelson PA, Christiansen MG, et al: Soccer players under regular training show oxidative stress but an improved plasma antioxidant status. Clin Sci (Lond) 1999 96:381-385.

33 Rietjens SJ, Beelen M, Koopman R, et al: A single session of resistance exercise induces oxidative damage in untrained men. Med Sci Sports Exerc 2007;39:2145-2151.

34 Kaikkonen J, Porkkala-Sarataho E, Tuomainen TP, et al: Exhaustive exercise increases plasma/serum total oxidation resistance in moderately trained men and women, whereas their VLDL + LDL lipoprotein fraction is more susceptible to oxidation. Scand J Clin Lab Invest 2002;62:599-607.
35 Demirbag R, Yilmaz R, Erel O: The association of total antioxidant capacity with sex hormones. Scand Cardiovasc J 2005;39:172176.

-36 Katalinic V, Modun D, Music I, Boban M: Gender differences in antioxidant capacity of rat tissues determined by $2,2^{\prime}$-azinobis (3ethylbenzothiazoline 6-sulfonate; ABTS) and ferric reducing antioxidant power (FRAP) assays. Comp Biochem Physiol C Toxicol Pharmacol 2005;140:47-52.

-37 Trevisan M, Browne R, Ram M, et al: Correlates of markers of oxidative status in the general population. Am J Epidemiol 2001; 154:348-356.

38 Nathan L, Chaudhuri G: Antioxidant and prooxidant actions of estrogens: potential physiological and clinical implications. Semin Reprod Endocrinol 1998;16:309-314.

39 Warren MP, Perlroth NE: The effects of intense exercise on the female reproductive system. J Endocrinol 2001;170:3-11.

40 Nikolaidis MG, Kyparos A, Hadziioannou $M$, et al: Acute exercise markedly increases blood oxidative stress in boys and girls. Appl Physiol Nutr Metab 2007;32:197-205.

41 Miller NJ, Rice-Evans C, Davies MJ, et al: A novel method for measuring antioxidant capacity and its application to monitoring the antioxidant status in premature neonates. Clin Sci (Lond) 1993;84:407-412.

42 Cao G, Prior RL: Comparison of different analytical methods for assessing total antioxidant capacity of human serum. Clin Chem 1998;44:1309-1315.

43 Fukai T, Siegfried MR, Ushio-Fukai M, et al: Regulation of the vascular extracellular superoxide dismutase by nitric oxide and exercise training. J Clin Invest 2000;105:16311639.

44 Schneider CD, Barp J, Ribeiro JL, et al: Oxidative stress after three different intensities of running. Can J Appl Physiol 2005;30:723734.

45 Banfi G, Malavazos A, Iorio E, et al: Plasma oxidative stress biomarkers, nitric oxide and heat shock protein 70 in trained elite soccer players. Eur J Appl Physiol 2006;96:483486

46 Metin G, Gumustas MK, Uslu E, et al: Effect of regular training on plasma thiols, malondialdehyde and carnitine concentrations in young soccer players. Chin J Physiol 2003;46: 35-39. 